\title{
Por una Poética imposible: La Academia Española y la obra de Luzán (*)
}

\author{
NICOLÁs MARÍN ( \\ Universidad de Granada
}

Basta acercarse al siglo XVIII y pisar sus umbrales para tropezar enseguida con algún testimonio de una nueva conciencia histórica $\mathrm{y}$, por ello mismo, crítica. Si ya lo es plenamente y con pocas excepciones en la segunda mitad de la centuria (con razón objeto preferente de análisis y estudio, aunque esa misma conciencia sirva en más de un caso para propugnar la vuelta a valores caducos), nada más apasionante que verla desperezarse entre las sombras - tan bellas, a veces - del otoño barroco. Hoy está probado que en la filosofía y en la ciencia los comienzos de esta edad de la razón, enredados en algunos equívocos o confundidos con las ya inertes novedades del Renacimiento, se adelantan hasta las últimas décadas del siglo XVII; una reducida minoría de esclarecidos españoles buscó - no sin riesgos- un cambio en esos campos de la cultura española, al que no era ajeno el ejemplo de Europa y sobre todo, inevitablemente, de la Francia de Luis XIV, contemporánea de los tristes días de Carlos II. No ocurrió lo mismo con el arte y con la literatura de creación, que no acusan novedades hasta bien entrado

\footnotetext{
* Insertamos en primer lugar, como homenaje a nuestro querido amigo el profesor $\mathrm{Ni}$ colás Marín, recientemente fallecido, el estudio que nos confió poco antes de su muerte.
} 
el 700. A medio camino entre ambas actitudes, en el campo de las doctrinas lingüísticas y literarias la voluntad reformista aparece ya muy a fines del 600 como fruto último de aquellas minorías ilustradas y cuaja definitivamente en 1713 con la erección de la Academia Española. Bien mirada, la nueva institución era un éxito final de aquel selecto grupo de novatores que, en torno al Marqués de Villena, consiguieron la protección del primer Borbón español; no tanto como resultado de una actitud paternalista heredada y paralela de la de su ilustre abuelo, sino más bien como un acto de independencia intelectual consciente fuertemente nacionalista; no en vano los años finales de la guerra de Sucesión, en la que la mayor parte de los españoles siguió las banderas de Felipe de Anjou, son precisamente los que traen un debilitamiento de la colaboración francesa, sobre todo en 1711, cuando ya se preparaba la paz del año siguiente, situación que hace crisis definitivamente en 1715 . De modo que no casualmente la Academia de la Lengua, llamada Española por privilegio de antigüedad, y luego la de la Historia, tuvieron un objetivo prioritario: la lengua y la historia de España. A una y otra podría aplicarse el lema de la primera: limpiar, fijar y dar esplendor es un triple fin que no tiene sentido más que desde una posición historicista, de reflexión sobre el pretérito. A los primeros académicos de una y otra institución les preocupaba el pasado español y estaban dispuestos a crear una nueva historia española limpia de fábulas y errores, y una filología basada primordialmente en los mejores escritores de las centurias anteriores. No es un azar que la expresión Siglo de Oro, esto es, Edad de Oro, surja ahora como una idealización del pasado que se contempla desde una última decadencia no ignorada ni ocultada y que resultó el estímulo más honesto para lograr una reforma pacífica ${ }^{1}$. Las primeras academias y, con ellas los primeros académicos, están más ocupados en sus primeros años en restaurar una España decaída que en alumbrar alguna clase de revolución intelectual.

En este sentido la actitud de la Academia Española es muy clara. En los estatutos que se dio en 1715 hay uno incluido como el primero de su capítulo V, «De las obras de la Academia», que dice así: «Fenecido el diccionario (que como va expresado en el Capítulo primero, debe ser el primer objeto de la Academia) se trabajará en una Gramática y una Poética españolas, e Historia de la Lengua, por la falta que hacen

1 Véase mi trabajo «Decadencia y Siglo de Oro», en 1616. Anuario de la Sociedad Española de Literatura General y Comparada, V, en prensa. 
en España» ${ }^{2}$. Si el método con que se hizo el Diccionario es tan bien conocido que hoy lo llamamos de autoridades por estar cada palabra y acepción autorizadas por su uso en un autor anterior, desde la Edad Media a los primeros años del XVIII, pero fundamentalmente de los siglos XVI y XVII, no es tan sabido que no más terminarlo a comienzos de $1740^{3}$, el 11 de agosto de ese año se decidía pasar a las dos primeras de las tres obras previstas en aquel estatuto citado; una semana escasa después, el 16, se establecía el modo de realizarlas y dos días más tarde se nombraban las comisiones de los que habían de ocuparse de redactarlas y presentarlas a la Academia para su revisión y posible aprobación ${ }^{4}$. Después de tan clara formulación de un viejo proyecto, conscientemente pospuesto hasta ese momento por la dedicación preferente al diccionario, no se entiende por qué el criterio tradicional y suspicazmente castizo de Menéndez Pelayo - que al menos pudo conocer los estatutos de su propia academia - lo llevó a exclamar como escandalizado que, a pesar de seguir ésta el modelo francés, nunca mostró «pretensiones de reglamentar el gusto» y que «jamás se le ocurrió legislar en la esfera retórica [...] La Academia no pensó formalmente en redactar una poética, por más que algunos escritores lo afirmasen en son de burla» ${ }^{5}$. No hay tal burla -acaso inducida por algún escrito de Mayans - sino un propósito firme, que incluso desde los primeros años había tentado a un Don Pedro Verdugo, que el mismo 1715 ya había compuesto una disertación sobre el numen poético, donde además prometía a sus colegas, lo que luego no hizo, unos paralelos entre los antiguos clásicos y los españoles modernos ${ }^{6}$. Corporativamente hubo, sin

2 Diccionario de la lengua castellana, I, Madrid, 1726, p. XXIX. En el estatuto siguiente y en relación con la elocuencia se dice: «Se encargará la Academia de examinar algunas obras de Prosa y Verso para proponer en el juicio que haga de ellas las reglas que parezcan más seguras para el buen gusto, así en el pensar como en el escribir». La crónica de la obra la ha hecho F. Lázaro Carreter en «El primer diccionario de la Academia», en Estudios de lingüística, Barcelona, Crítica, 1980, pp. 83-148.

3 La fe de erratas del último volumen es de 22 de diciembre de 1739 , por lo que salió a la calle ya en el año siguiente.

4 Según las actas, conservadas en la secretaría de la Academia, a la que quiero agradecer públicamente las facilidades que me ha dado para la consulta de estos y otros papeles.

5 Historia de las ideas estéticas, ed. de Madrid, 1947, III, pp. 196 y 198.

6 Véase mi trabajo «Poesía y ciencia moderna en un texto de 1715 », en Serta Philologica F. Lázaro Carreter, II, Madrid, 1983, pp. 317-327. 
embargo, que esperar al año 40, en que se replantea la realización de la poética y de la gramática. Es importante señalar que si de la segunda se anticipó muy pronto y separadamente la ortografía (aparecida al año siguiente, 1741) lo demás de la gramática se retrasó hasta muy tarde, el año 1771 , con unos criterios ya bien diversos a los del proyecto inicial $^{7}$; aunque es poco conocido el dato, el método de la nonata gramática de aquel año 1740 era exactamente el mismo que el del diccionario: el uso de la lengua estaría justificado en cada caso por los mejores escritores del Siglo de Oro ${ }^{8}$. Se proyectaba, pues, una gramática de autoridades paralela al diccionario ${ }^{9}$.

En cuanto a la composición de una poética española, cabría pensar que la propia redacción de las obras citadas y la revisión del diccionario hicieran inevitable su aplazamiento sine die. Sin embargo, me parece que el abandono del proyecto de la poética está estrechamente vinculado a la intervención del académico madrileño y regidor perpetuo de la Villa de Madrid Antonio Gaspar de Pinedo, precisamente uno de los tres comisionados en agosto para ello, que leyó en octubre una inédita y muy clara, más que elegante, Disertación sobre las dificultades de escribir la poética española ${ }^{10}$. Como es bien sabido, la Academia mantenía entonces el precepto inicial de que por turno los académicos hicieran una disertación que no pasase de media hora de lectura; esto

7 Gramática de la Lengua Castellana, compuesta por la Real Academia Española, Madrid, 1771.

8 En el proyecto de 1740 los escritores que iban a autorizar el uso de la lengua fueron los siguientes, repartidos a los distintos académicos: el P. Pedro de Ribadeneyra, Fray Luis de Granada, Diego Hurtado de Mendoza, Luis Muñoz, Lazarillo de Tormes, Luis de Ulloa, Fray Luis de León, Pedro Simón Abril, los dos Leonardo de Argensola, el Marqués de Mondéjar, E. M. de Villegas, E. Nieremberg, Pedro Calderón, Santa Teresa de Jesús, Fray Hernando de Santiago, el P. Yepes en su Vida de Santa Teresa, M. de Cervantes, A. de Solís, Luis de Góngora, Anastasio P. de Ribera, Gonzalo Pérez, F. de Quevedo, el P. Pedro de Abarca, F. F. Monteser, el P. Juan de Ávila, el P. Hortensio Paravicino, Cepeda, D. de Saavedra Fajardo, B. Gracián, F. L. de Villalobos, B. Alderete, Juan de Mariana, Luis de la Puente, el P. Parra, el Guzmán de Alfarache de M. Alemán y el Felipe II de Cabrera de Córdoba. Aunque el total es muy inferior al del Diccionario, todavía están muy presentes los autores del XVII.

9 En ambos casos, cuando los años pasaron, el método académico varió profundamente: del criterio de autoridad se pasó expresamente al de la razón y la lógica; tanto la gramática nueva como el diccionario de 1780 dejaron de apoyarse en el uso de los escritores.

10 Conservada en el archivo de la Academia, autógrafa, sin fol., con 47 notas al margen, que son 49 por repetirse la 19 y la 31 . Me he servido de ellas para algunas mías, 
es lo que hizo Pinedo el 27 de aquel mes de 1740: explicar por qué era difícil escribir una poética académica. Aunque el escrito no sea una pieza literaria de primer orden, tiene a mi parecer una importancia decisiva para la institución por las razones que señalo más abajo. Si se quisiera definir en pocas palabras en qué consiste, habría que señalar que, aunque no niega la utilidad de unos principios generales, no está convencido en absoluto de la posibilidad de imponerlos sobre la natural inspiración de los poetas; en todo caso, si la Academia quiere hacerlo así, la decisión llega algo tarde porque Luzán acaba de efectuarlo poco antes, al publicar a fines de 1737 su Poética:

Premiando el deseo como si fuera mérito - dice Pinedo en un retórico exordio- se sirvió V.E. incluir mi humilde pluma en el número de las tres que destinó a escribir la poética española; ya fuese porque a la inclinación de facilitarme tal honra no se le descubrió todo el reparo de mi insuficiencia, o porque, supliéndose ésta con las otras notorias excesivas ventajas, quedó en el favor de V. E. compatible el acierto de la obra con el no merecido honor de trabajar yo en ella [...] Pero confieso que, ya más cercano a su ejecución, me sonroja mucho el conocimiento de la inutilidad y me atemoriza no poco la justa censura de temeraria que habrá de darse a mi resignación...

No es éste el tono general de su papel, en el que todavía pone una nota erudita, una anécdota contada por Séneca ${ }^{11}$, y entra en materia con estilo y actitud mucho más ágiles.

El punto de partida es obviamente el arte, entendido como «una recta razón de lo factible» (definición escolástica, anotada expresamente) que se compone de «los preceptos que aprobaron el uso y la experiencia». Pinedo se coloca en un principio en una postura normativa, que pronto se descubre como flexible, ya que la poética «admite la variedad y la duda que en la ciencia no caben». No obstante, es útil y conveniente reunir las reglas posibles, «antes vagas y dispersas», principio que le lleva inmediatamente a una investigación histórica, al inquirir los orígenes de ese hecho; ¿qué fue antes, la poesía o la poética, esto es, la obra poética o las normas que se dicen imprescindibles?:

en las que he completado referencias o añadido algún detalle. Una vez leída, otra mano que creo del Secretario añadió a los autores españoles de poéticas a «Juan de la Encina y antes de él los trovadores y Villena»; y en la cubierta: «Para unida con la del señor Conde de Torrepalma padre, añadiendo Españoles que escribieron antes de Rengifo y lo que Juan Bautista Vico pretende y se esfuerza a probar que primero se habló en verso que en prosa. Es muy digna por lo demás».

11 De beneficiis, lib. 6, cap. 11, que parece interpretar de modo muy personal y no como lo explica el latino. 
Aunque el congregarlas no fue producirlas, con todo eso se alzaron por este trabajo muchos hombres no sólo con el título de inventores, si no es de deidades entre la ceguera idólatra de los egipcios, de cuyo nocivo comercio adquirió el estudioso genio de los griegos las luces de las facultades entre el humo pestilente de los falsos dioses [...] Siguiendo por este rumbo sus delirios, fue otro de los muchos hacer a Apolo inventor y dios de la armonía.

Si este comienzo de la poesía es fabuloso hasta llegar así a los latinos, no lo es menos el que lo pone entre poetas como Orfeo, Olimpo, Siagrio, Museo o Lino, de lo que «quedó sólo creíble su respetable ancianidad, pues antes del diluvio llama Moisés a Jubal padre de los que cantaban con cítara y órgano» ${ }^{12}$. La mezcla de candor y racionalidad está, empero, muy presente en el párrafo inmediato donde ya afronta la cuestión claramente: «Si se hallasen tan antiguas reglas de arte poética como se encuentran poesías en que resplandece el arte, sería prueba evidente de lo preciso que fue éste para la perfección de aquéllas».

Pinedo, así, no abandona el terreno histórico, aludiendo a lo que se cuenta de que Píndaro escribió por las reglas que le dio Laso de Hermión ${ }^{13}$; pero, en dirección contraria, es un hecho que Píndaro murió en la olimpiada ochenta y seis $^{14}$ y Aristóteles nació en la noventa y nueve, con lo que se ve que «a los preceptos de este insigne varón habían precedido los que usaron Píndaro, los trágicos Esquilo, Sófocles, Eurípides y otros muchos anteriores poetas», entre ellos el más antiguo y celebrado Homero. Pinedo no parece comprender que la poética de Aristóteles, todo lo incompleta que se quiera, fue justamente resultado de una observación de la práctica anterior más que una norma original y previamente establecida, pero desde su perspectiva, en realidad asumida ya por algunos desde el Renacimiento, su interpretación apoya muy claramente la tesis contraria a una supuesta necesidad de preceptos. La posición del académico, que adelanta la fórmula de Llaguno cuando afirmaba que «antes hubo Homero que Aristóteles», se origina en una cita de José Antonio González de Salas en su Nueva idea de la tragedia antigua, al decir que «no faltaron antes [de Aristóteles] famosos poetas, que con sólo el feliz preceptor de la naturaleza llegaron al sumo

12

13 
grado en su profesión», cosa que, por otra parte, atestiguó ya de otra forma el mismo Cicerón ${ }^{15}$.

Por todo ello, a Pinedo le importa en su argumentación situarse, sin violencia desde luego, entre los que, con un pie en ese principio, se atreven a mantener que la poesía es antes natura que ars: «No digo que se admita aquel supersticioso hipérbole de llamarlos [a los poetas] divinos y arrebatados del furor que les infunde superior numen, como escribieron Platón, Ovidio y otros muchos». Es esta cita, ya clásica en el tratamiento de la inspiración poética, ante la cual Pinedo se muestra muy cauto, como lo fue ya su antecesor Verdugo en el análisis del numen: «Me parece razonable - escribe Pinedo- la opinión de que lo que llamamos vena en los poetas es una vehemencia perspicacísima del genio, que suministra copiosas imágenes a la fantasía, cuyas especies no podría adquirir sin este don gratuito de la naturaleza». Quien así se expresa está cogido entre dos posiciones antitéticas, sin acabar de encontrar o de querer encontrar una solución definitiva al problema; lo queno se cuestiona es una suerte de inspiración moderada que lleva a los poetas a escribir versos. Se diría que nuestro autor no quiere romper con la tradición del respeto a la preceptiva clásica, pero que está íntimamente inclinado a un impreciso concepto de inspiración.

Es en este punto donde Pinedo abandona toda pretensión metafísica en el seguimiento del análisis poético al plantear sin más lo que constituye ya la segunda parte del problema: supuesta esa «vehemencia perspicacísima», ¿qué es lo esencial, la imitación o el verso? Según Pinedo, que tampoco ahora va a inclinarse decididamente por ninguna solución, Aristóteles se adhiere claramente - como bien sabemos - a «la imitación de la naturaleza con ficciones verosímiles, no dando a los versos por distinción formal del poeta», como en efecto lo afirma en el capítulo primero de su obra ${ }^{16}$, aunque Pinedo lo cita en este caso a través de González de Salas: «Heródoto en versificación numerosa no dejaría de ser historiador, ni Homero dejaría de ser poeta, aunque se disolvieran en prosa sus poemas». Si ello es así y lo esencial es la imitación, no serán poetas los que tienen gran facilidad para componer espontáneamente versos, cosa que ya preocupó a los comentadores del Estagirita; pero no es menos cierto que a los de Horacio les ocurre lo mismo: «Yo no sé cómo desatar esta dificultad, ni en qué consiste la varia estimación

is González de Salas, op. cit., «Introducción», fol. 4.

16 Aristóteles, Poética, I, 1447b. 
que ha tenido el verso en cuanto a su principalidad en las poesías griega y latina y aun en la italiana y la francesa».

A este propósito, parece como si Pinedo lamentara la inevitable desvalorización de los testimonios sobre la facilidad de versificar: el conocido de Ovidio y el de Sor Juana Inés de la Cruz, insólito en esta clase de escritos académicos:

Quisiera acertar a explicarme con el ejemplar y autoridad oportuna de la insigne poetisa mejicana, quien escribiendo a su Filotea con la ingenuidad religiosa y correspondiente a la autorizada persona que recibió y estampó la carta, dice serla tan natural su perseguida habilidad de hacer versos que se violentaba para que aquel escrito no lo fuera; bien pudiera creerse que cuando Ovidio hizo igual expresión fue galantería ufana de su destreza, pero en aquella virtuosa pluma merece estimación de sincera verdad, que confirma la bien recibida opinión de que en la poesía todo lo más es naturaleza, tocando lo menos de ella al arte ${ }^{17}$.

Hasta aquí, poco más de mediada su disertación, Pinedo ha presentado de modo impecable su equilibrada argumentación para llegar a la alternativa final. Sin embargo, interesa más notar que junto a Séneca o San Jerónimo, y desde luego Aristóteles y Horacio, está el conocimiento de otros problemas y otros textos menos frecuentes en los teóricos de la poesía, como es el caso de la misma Sor Juana Inés, muy significativo por su carácter barroco. En primer lugar, la cita de Homero como antiguo poeta y príncipe de la épica griega, muy anterior a todo escrito didáctico, da pie a un excurso en el que, sin advertirlo expresamente, Pinedo se explaya en un aspecto de la cuestión homérica. El caso es que ello se había replanteado vigorosamente desde fines del siglo XVII en Francia, lo que parece conocer nuestro académico; no otro sentido tiene el separarse del hilo del discurso si no es por sentir como

17 «Pues si vuelvo los ojos a la tan perseguida habilidad de hacer versos —que en mí es tan natural, que aun me violento para que esta carta no lo sean, y pudiera decir aquello de Quidquid conabar dicere, versus erat-, viéndola condenar a tantos tanto y acriminar, he buscado muy de propósito cuál sea el daño que puedan tener y no le he hallado», dice Sor Juana en su «Respuesta a Sor Filotea de la Cruz», en Obras completas, IV. ed. de Alberto G. Salceda, México, 1957, pp. 469-70. La obra de Sor Juana apareció ya incluida en el tomo III de Fama y obras pósthumas del Fénix de México, décima musa, poetisa americana, Sor Juana Inés de la Cruz [...], Madrid, 1700, con reediciones hasta 1725. En cuanto a Ovidio, su texto está en Tristia, IV, $x$, 25-26: Sponte sua carmen numerus veniebat ad aptos / et, quod tentabam dicere, versus erat. Esta referencia, que era ya lugar común, vuelve a aparecer en un romance de la misma autora, en que excusándose de escribir en verso dice: «Si es malo yo no lo sé; / sé que nací tan poeta, / que azotada como Ovidio, / suenan en verso mis quejas». 
algo de actualidad próxima el tema del origen, patria y carácter del autor de la Ilíada: «¿A quién debería Homero tanta excelencia como llamarle príncipe de todos ellos, si hubo de ser a fuerza de preceptos la singularidad de sus obras?» Con esto hubiera bastado, pero Pinedo se extiende en este largo párrafo, después de plantear la duda habitual sobre su lugar de nacimiento:

El Barón de Tournefort en su Viaje a Levante dice que en Esmirna testifica el arroyo Meles la etimología de donde tomó el primer nombre Melesígene, por haber nacido en su orilla, cuyo suceso afirman por tradición aquellos naturales, pero que los de la isla de Scío muestran en la capital de este nombre las ruinas de la casa en que vio la luz primera y las de la escuela donde enseñaba, sin que por esto dejasen los de la isla de Nío (antiguamente Io) de enseñar el sitio de su sepulcro y de la columna con su estatua que allí hubo; conque esta porfía basta que dure en solos estos parajes de Grecia para no dejar esperanza de saber lo cierto. Por lo que toca al tiempo en que vivió no es menos la diferencia que de tres o cuatro siglos lo variaron los escritores, hasta que en esta oscuridad han dado luz las inscripciones de los mármoles que en la Universidad de Oxford sirven de adorno al teatro de Sheldon, recogidos por los muchos gastos y diligencias del Conde Tomás de Arundel, infiriendo los eruditos por aquellos antiguos monumentos que Homero vivía 907 años antes de nuestra salud.

Todas estas cuestiones habían sido ya discutidas en la última fase de la famosa querella de los antiguos y modernos, a que me refiero más abajo, a partir de la publicación en 1699 de la traducción de la Ilíada por Madame Dacier -desaparecida en 1729 y bien conocida en España-, a la que replicó Antoine de la Motte Houdart con otra poco fiel; ello estimuló a la misma Dacier, en 1714 ya, a publicar De las causas de la corrupción del gusto, que Luzán cita con frecuencia. Se establecía así, sobre el fondo de la cuestión de la superioridad de los modernos, una polémica no definitivamente acabada hasta unos años después. En el escrito de Pinedo es significativo el uso que al hilo de su argumentación hace de una bibliografía relativamente reciente, que contrasta con sus otras fuentes de información. El libro de Tournefort, $R e$ lation d'un Voyage au Levant, que había aparecido en París en 1717 le informa sobre el tema del lugar de nacimiento de Homero ${ }^{18}$, en tanto que el de James Beeverell, a través de su traducción francesa, le sirve para la cuestión de la época en que vivió, con la especial referencia al gran coleccionista Thomas Howard, Conde de Arundel (1585-1646), que

18 Josep Pitton de Tournefort, Botánico y viajero francés (1656-1708), encargado de visitar Levante y Africa por Luis XIV; fruto de su viaje fue la citada Relation, póstuma. 
hizo llevar a Inglaterra los célebres mármoles de Paros con una cronología de la historia griega desde el 1528 al 264 a. de C. ${ }^{19}$.

Aunque sin entrar en ellos, Pinedo conoce, desde luego, a los comentaristas de Aristóteles, como F. Benius, y los de Horacio, como Robortelli y antes de él Aldo Manucio, Policiano, Erasmo, Celio Rodiginio y otros autores antiguos, como Faustino Summo; pero nuestro académico no los confunde con los más modernos, pues ya al fin de su argumentación general sobre lo esencial de la poesía confiesa no ver claro el papel del verso no sólo en la poesía grecolatina, sino en las modernas poéticas italiana y francesa «que con prolijas reglas han pulido Giuseppe Malatesta, el Conde Monsigniani, Antonio Minturno, el Muratori, el Gravina, el Padre Rapin y otros muchos». Salvo el Minturno, los demás corresponden a los últimos años del XVII o comienzos del mismo XVIII.

En cualquier caso, con este prefacio de conclusión y compendio de autoridades, Pinedo se dirige inquisitivamente a la crítica española, pues no ha olvidado que de lo que se trata es de saber si es posible una poética española:

En esta confusión - dice- preciso era consultar nuestros escritos castellanos, y encontrando primero el que todos hallan y compuso Juan Díaz Rengifo siglo y medio ha, veo que, confesando florecer mucho entonces en España la poesía, se queja al mismo tiempo de ser muy pocos o raros los que en ella sabían el artificio poético por falta de reglas en que aprenderle; diólas a luz el año de 1592 con título Arte poética y a ésta la definió «hábito o facultad del entendimiento, que endereza y rige al poeta y la da reglas y preceptos para componer versos fácilmente».

Como una mano posterior, probablemente la del secretario de la Academia, ha señalado al margen, ignoraba Pinedo que antes de Rengifo estuvieron Juan de la Encina y antes de él los trovadores y Villena. No debe, por el contrario, sorprender el interés manifestado por Rengifo, cuyo texto, completado por Castillo y Mantilla en su forma definitiva y más conocida, iba a ser pronto blanco de innumerables burlas de los neoclásicos, que no podían creer con toda razón que la poética pudiera ser solamente arte de hacer versos, y versos enrevesados y perversos $^{20}$; pero ocurre que para Pinedo el problema está precisamente de Oxford. El libro de Beeverell va citado por Pinedo como Delices de Inglaterre. nantes..., publicada por su hermano Juan en Salamanca, 1592; nueva edición aumen- 
- supuesta la necesidad de una poética- en decidir si lo esencial es la imitación o la producción correcta de los versos. De ahí que sospeche que «Rengifo no tendría por versos [...] los que después compuso con tanta elegancia don Fernando Castillo en su Sagrada Erato, traduciendo los salmos de David, ni los que escribió don Francisco de Quevedo en la traducción de Focílides y otros de igual medida heroica», como pueden ser algunos de Villegas, sueltos sin rima ${ }^{21}$. En opinión de Pinedo - claramente errada- el concepto de poesía como mera composición en verso quedó admitido de modo permanente hasta sus mismos días:

Esta pacífica posesión se ve interrumpida por don Ignacio de Luzán, que, con erudición copiosa y sutil pluma acaba de dar a luz una nueva poética española, a quien define «arte de componer poemas y juzgar de ellos», y a la poesía «imitación de la naturaleza hecha con versos particular o universalmente para deleite o utilidad, o para ambas cosas juntas», y a la imitación «fingimiento de sucesos verisímiles o enérgica relación de los verdaderos»; al verso «medida de palabras», para excluir el sonido y estilo ${ }^{22}$.

Esto es, Luzán se opone de modo radical a Rengifo, bien que esto sea una simplificación abusiva de la historia, puesto que al menos Pinedo no ignora a los autores que ha citado antes y conoce particularmente la doctrina aristotélica a través de González de Salas.

Sin embargo, el hecho de dedicar esta su segunda y más breve parte de la disertación a Luzán es de importancia. Este escrito hasta ahora inédito es, si no me equivoco, uno de los primeros juicios sobre una obra que había sido recensionada y valorada en el Diario de los literatos apenas aparecida (tomo IV, 1738) y se coloca, en 1740 , antes de que salieran a la luz el Discurso apologético de Inigo de Lanuza en 1741 y la Carta latina de Ignacio Philaletes, en 1742; no es fácil saber si en esa defensa de su obra esconde Luzán alguna alusión a las palabras de Pinedo, en el supuesto poco probable de que llegaran a sus oídos; el académico comprendía bien la importancia de La Poética, que había leído

tada por José Vicéns en 1606. Gabriel del Castillo y Mantilla publicó su Laberinto poético..., en Madrid en 1691.

21 El nombre de Villegas y sus Eróticas lo añade Pinedo en su nota 31.

22 Pinedo debía de haber leído bien La Poética y citar de memoria, pues equivoca el tenor literal de la segunda cita, que Luzán escribió así en su Libro I, cap. 5: «Imitación de la naturaleza en lo universal o en lo particular hecha con versos, para utilidad o deleite de los hombres o para uno y otro juntamente», pág. 161 de la excelente edición de Russell P. Sebold, Barcelona, Labor 1977, con la que he cotejado todas sus citas. 
ya con atención, y se refiere siempre a su autor con respeto ${ }^{23}$. Lo que no es fácil de entender para él, como núcleo de una posición crítica global, es que si lo importante es la imitación, que depende de ciertas cualidades personales y en último término de la naturaleza, pueda lograrse con los preceptos. Por supuesto que, si ello es así, el verso pierde toda su importancia: «Pero venerando las doctas reflexiones de este autor, me parece que en lo mismo que omite por no importante [la versificación] es en lo que puede adelantar el arte, y lo que propone enseñar como preciso [la imitación] es lo que sólo puede adquirirse por naturaleza». Esta afirmación crítica, central en la argumentación de Pinedo, lo sitúa en una posición conservadora, de recelo ante una obra de positiva importancia. Me imagino que ello no es sólo una cuestión que deba para él dirimirse simplemente entre versos o imitación, sino que tiene unas causas más profundas, según lo que dice a continuación:

Supóngase norabuena que la sabiduría griega no dio más que un Homero, la romana un Virgilio y la moderna italiana un Torcuato Tasso, como dice Antonio López de Vega ${ }^{24}$, y que ninguno otro llegó a la alteza épica cumpliendo exactamente con los preceptos de la epopeya, ¿con qué medios se nos facilita el igualarlos? Con la invención verisímil de sucesos raros de héroes perfectos, con la doctrina moral que éstos produzcan, con lo sublime y propio del estilo, con el buen uso de tropos y figuras, con los bien entretejidos episodios... Con todo esto y lo demás que Luzán propone se hace una perfecta epopeya, pero ¿por dónde se aprende todo esto? Por el ingenio juicioso, por la erudición abundante, por la viveza de la fantasía: ;oh, si hubiera un arte que lo enseñara!

En parecidos términos se expresa Pinedo en su aguda crítica a Luzán a propósito de la lírica y de la sátira. Pero donde la argumentación se hace más tensa e interesante es en la dramática, cosa que no puede sorprender: el siglo XVIII entero no hizo más que reavivar una vieja polémica; no es casualidad que Pinedo derive en sus observaciones a una defensa del teatro presente con un tono ciertamente comedido frente a las censuras de Luzán y que, aunque sin particular intención, recuerde la polémica de antiguos y modernos:

Hiciera igual reflexión sobre la dramática - y no la hace-, intentando probar que la tragedia antigua pudo ser entonces gratísima diversión y ahora sería intolerable festejo, y que la comedia presente ni merece la rigurosa críti-

Del libro de Luzán proceden también la definición escolástica del arte y la noticia de Florián de Ocampo sobre la estancia de Homero en España, incluidas ambas en la aprobación del $\mathbf{P}$. Navarro.

Heráclito y Demócrito de nuestro siglo, Madrid, 1641. 
ca que Luzán hace de ella, ni tiene que envidiar las alabanzas del griego Menandro, ni de los latinos Terencio, Plauto, Nevio, Trabea, Turpilio, con todos los más celebrados cómicos, pero no permitiéndolo el tiempo, sólo diré brevemente que aquella estimación con que regularmente miramos todas las cosas que más lejos están de nosotros, dándoles la sucesión del tiempo una digna veneración, no debe disminuir tanto el aprecio de las presentes que las despojemos de su merecida alabanza por dar a la antigüedad todo el aplauso.

La primera frase sigue muy de cerca conceptos sobre la tragedia esgrimidos ya por los defensores de Lope un siglo antes; apenas se detiene en ellos, puesto que aún no existen las nuevas, desde Montiano a Cienfuegos, por señalar dos distantes ejemplos del mismo siglo y con las cuales había de establecerse más tarde larga disputa. Para entender lo que de la comedia sigue diciendo Pinedo habría que saber previamente de qué teatro está hablando, cuando se afirma que la comedia presente no merece la rigurosa crítica que Luzán hace de ella desde el comienzo mismo de su libro. Porque aún no estamos ante la nueva comedia clásica, la de un Iriarte o un Moratín, que llegaron a tener, contra lo que suele creerse, su público adicto, y a la cual Luzán en todo caso no había de censurar, ni tampoco estamos en los tiempos dorados de lo mejor de Lope y de Calderón, a los que alude con frecuencia el autor de $\mathrm{La}$ Poética; el término presente en Pinedo hay que entenderlo en sentido lato, porque entonces lo representado era, junto a aquellas grandes figuras, la producción de Cañizares, Hoz o Zamora, y más aún, adaptaciones y refundiciones de piezas muy anteriores con abundancia de tramoya espectacular.

A Pinedo la censura de Luzán le parece excesiva e injusta, porque no quiere ver en los antiguos los defectos que ve en los modernos:

Rigor es que el defecto de unidad de tiempo o cualquier otro error de paraje o de persona se haya de notar severísimamente en los más lúcidos poemas españoles y que no sea reparable en la Eneida de Virgilio que resucite a Dido para que Eneas la enamore después de dos o tres siglos que había fundado a Cartago y muerto; que censuren gravemente la falta de verisimilitud en cualquier descuido de nuestros poetas y se califique de tan semejante a lo posible, después del peregrino milagro que hizo Palas en la fábrica de un caballo del tamaño de un monte, el acomodar dentro de él sin nuevo prodigio todo el crecido número de soldados que dice y corresponde a los ocho caudillos que nombra; y que, estando así atestado, resonase hueco el vientre al golpe de la lanza de Laocon; que una vez subiese aquella máquina sobre ruedas por la muralla y otra diga que entrase por la puerta, parándose en ella; y a esta manera otras circunstancias que, si bien se observan, se necesita para su credulidad toda la sencillez con que en aquellos tiempos disculpa Luzán el que también Homero ocupase un héroe en espetar en el asador una oveja.

Volviendo de esta digresión al objeto central de su disertación, se pregunta Pinedo que «si el mismo Luzán confiesa que el artificio poéti- 
co es el ingenioso modo de decir las cosas y que el saber expresarlas es tan delicioso como inventarlas con perfección, ¿por qué este nuevo y erudito autor quiere que todas las reglas poéticas se apliquen principalmente a la invención que ha de hacer el ingenio y no a los que sólo llama esclavos versos que han de explicar sus conceptos?» Indudablemente, Pinedo no acepta las reglas como apropiadas a la fase de inventio, según la denominación retórica, ni puede aceptar que la composición de los versos quede en una situación secundaria.

Sin embargo, el escrito académico - tan ponderado y al mismo tiempo tan lleno de reservas frente a Luzán - termina con claridad meridiana y una disyuntiva impecable: "Concluyo este discurso - dice con afectada humildad - para que la brevedad le haga menos malo y para significar a V.E. que al tiempo que sus estatutos dispusieron formar la poética española no pudo tener presente se había de adelantar a cscribirla don Ignacio de Luzán, cuya novedad ocasiona la de que si ha de practicarse el estatuto es menester copiar a Luzán o contradecirle». Imposible opción, que, aunque probablemente Pinedo se hubiera inclinado por lo segundo, determinó en el ánimo de sus oyentes la suspensión del proyecto. Ni se le contradijo ni se escribió otra.

Se habrá notado que en toda ocasión tanto la Academia como Pinedo no hablan de una poética en general, lo que sería natural dado que las ideas literarias parecen no tener patria y que son conceptos abstractos o universales; así llegaría a pensarlo el mismo Luzán más adelante al escribir en la edición de 1789 que «una es la poética y uno el arte de componer bien versos, común y general para todas las naciones y para todos los tiempos; así como es una la oratoria en todas partes; y por los mismos principios y medios por donde fueron tan elocuentes Demóstenes, Esquines y otros entre los griegos, io fueron también Cicerón, Antonio, Hortensio y otros entre los romanos, y lo han sido entre nosotros un maestro Oliva, un fray Luis de Granada, un fray Luis de León, un Mariana, un Solís...» Las diferencias nacionales son escasas: «en ciertas circunstancias accidentales puede hallarse, y se halla con efecto, alguna diferencia» ${ }^{25}$. Pero en 1737 y años siguientes Luzán, como Pinedo, no estaba tan seguro de ello y sentía con claridad las diferencias nacionales, hablando así con un cierto afán patriótico en su capítulo I, que sirve de proemio al libro y que me parece pieza esencial para comprender su alcance y sentido: «En estos últimos siglos, espe-

Poética, ed. cit., cap. IV de 1789, p. 147. 
cialmente en Italia y Francia, se han escrito tan cabales tratados de poética, tantas y tan doctas críticas, tan ingeniosas apologías [...] que ya parece que estas naciones no pueden desear más luz ni mejores guías para caminar, sin tropiezo ni extravío, la vuelta del Parnaso. Sólo en España, por no se qué culpable descuido, muy pocos se han aplicado a dilucidar los preceptos poéticos...» Lamento que comparte el $\mathrm{P}$. Navarro en su aprobación, al hablar del autor del libro: «Supone éste, al fin de la página 3, que Italia y Francia no tienen más que desear en el punto de entender la poética, y que sólo en España son pocos los que se han aplicado a elucidar los preceptos de ella. Cáusame dolor que padezca nuestra nación tal omisión» ${ }^{26}$. En efecto, la existencia y mención de González de Salas o de Cascales, con exclusión expresa del Arte nuevo de Lope, no puede compararse con la variedad y cantidad de autores no sólo antiguos, sino franceses e italianos, aunque en la segunda edición tan parva nómina se viera aumentada. De franceses e italianos también había tomado buena nota el propio Pinedo en la cita ya copiada arriba (Malatesta, Monsigniani, etc.) antes de «consultar nuestros escritos españoles», marcando así los respectivos campos nacionales.

En este punto es obligado aludir a las fuentes de la poética de Luzán, tan discutidas por la crítica moderna y que con tanta precisión y exactitud ha probado Russell P. Sebold ser esencialmente de origen clásico, y a que La Poética es española por el uso que hace en sus juicios de un material literario básicamente español ${ }^{27}$. Creo que ello podría matizarse además por el hecho de que La Poética es, según la presenta el proemio, un comentario de un español y escrito en la lengua española de la poética clásica, centrada en Aristóteles ${ }^{28}$, y en el que los italianos y los franceses son simples medios bibliográficos auxiliares, sobre cuya preponderancia no es preciso discutir mucho. Tengo la impresión de que durante los años de su composición, los anteriores a 1737, Luzán sentía casi lo mismo que la Academia en su atareado trabajo filológico: la necesidad de una evaluación de la cultura nacional, tan decaída a principios de siglo. Me parece que el avance de las ideas neoclá-

26 Poética, ed. cit., Cap. I de 1737, p. 124, y aprobación de Navarro, p. 104, respectivamente.

27 «Análisis estadístico de las ideas de Luzán: sus orígenes y su naturaleza», en El rapto de la mente, Madrid, Prensa Española 1970, pp. 57-97.

28 Cfr. «The Reintroduction of Aristotelian Rules of Cristicism in Spain through Luzán's Poética», en The Neoclassic Movement in Spain during the XVIII Century, Stanford Univ. Press, 1918, págs. 23-48. 
sicas llevó a los intelectuales, a los académicos y a Luzán mismo a pensar años después, a partir aproximadamente de 1750 , que la nueva cultura clásica era una cultura internacional basada en unos ideales comunes y que el pasado español, ya que no podía ni debía ser aniquilado, sí habría de ser juzgado con severidad. En 1737, sin embargo, La Poética fue todavía, aunque con más rigor, como el diccionario y la prevista Gramática, una poética de autoridades; a ello probablemente se debe el sabor ecléctico que deja en algunos lectores. Bien es cierto que la literatura barroca no sale bien parada en todo, pero ni se la condena completamente, como algunos creen todavía, ni se deja de ponderar en ella a muchos ingenios del XVI y comienzos del XVII. La seria poética de Luzán, por mucho que tenga de nuevo, es todavía una poética ligada estrechamente a un pasado, ya cerrado y concluido, pero que de ninguna manera puede dejarse a un lado.

Quiero creer que, de alguna manera, esa obra de Luzán, que vino a interponerse en los deseos de la Academia, fue a su vez y en cierto modo la Poética académica: si Pinedo, desde fuera de la comisión oficial, puso respetuosamente objeciones a su autor, éste entró muy pronto en la docta casa: en 1741 era elegido miembro honorario y en 1742 supernumerario ${ }^{29}$. Todo esto, que responde básicamente a hechos probados, explicita claramente no sólo el sentido de las primeras acciones de la Academia sino el lugar que la obra de Luzán tuvo en ellas. El propósito académico de componer una poética se convirtió en irrealizable, porque los académicos no quisieron copiarlo ni se atrevieron a contradecirlo. Optaron por otra cosa más sencilla: convertir a don Ignacio en académico.

29 Por falta de asiento y por su ausencia en París, Luzán no fue académico de número hasta 1751. 